\title{
The Effect of Rapid Microwave Sintering Process on the Electrical Conductivity, Thermal Conductivity and Mechanical Properties of Al-TiC Composites
}

\author{
Omid Yaghobizadeh ${ }^{a}$, Maryam Nazari $^{\circledR}{ }^{\oplus}$, Mehri Mashhadi ${ }^{b}$ \\ ${ }^{a}$ Department of Materials Engineering, Imam Khomeini International University, Qazvin, Iran \\ ${ }^{b}$ Faculty of Materials and Manufacturing Engineering, Malek Ashtar University of Technology, Tehran, \\ Iran
}

Received: May 04, 2018; Revised: August 06, 2018; Accepted: August 29, 2018

\begin{abstract}
In this research, electrical conductivity, thermal conductivity and mechanical properties of the AlTiC composites which were sintered via microwave-assisted process were investigated. The specimens were sintered for 3, 5 and 8 minutes. The results have shown that the sample which contains 4 vol. $\% \mathrm{TiC}$ and was sintered for 8 minutes, has the highest electrical and thermal conductivities among the other obtained ones. Besides that, the sample which contains 8 vol. \% TiC and was sintered for 3 minutes, has dedicated the highest hardness and density to itself. Scanning electron microscopy (SEM) micrographs have illustrated that by increasing the amount of TiC up to $12 \mathrm{vol}$ \% , the agglomeration of particles occurs. The X-ray diffraction (XRD) investigations have shown that due to the short duration of the sintering process in the microwave method, there is no trace of $\mathrm{TiO}_{2}$ and $\mathrm{Al}_{4} \mathrm{C}_{3}$ as pernicious phases. According to the obtained results, it becomes clear that increasing the amount of $\mathrm{TiC}$ powder leads to the reduction of electrical and thermal properties of the samples and increasing the sintering duration, leads to the increase of the mentioned properties.
\end{abstract}

Keywords: Microwave-assisted sintering, electrical conductivity, thermal conductivity, Al-TiC composite, Microstructure.

\section{Introduction}

Nowadays, metal matrix composites (MMCs) have caught so many attentions due to their unique properties including high specific modulus, high yield stress, wear resistance and good creep and fatigue properties. These composites have been utilized in so many applications such as aerospace industry, automobile industry, military applications and other high-tech innovations.

Among the light weight alloys, aluminum alloys are one of the best candidates for the fabrication of $\mathrm{MMCs}^{1-4}$. Due to the supreme features of Al, including low density, proper strength, high thermal and electrical conductivities, good strength and hardness, it can improve the final properties of composites if it be located as the matrix phase. Aluminum alloys have been studied from 1920s and various industries take them into great consideration ${ }^{3}$. Copper and/or aluminum due to good thermal conductivity, have been utilized usually as the baseplate of power module, but their CTEs are larger than the CTEs of ceramic substrates or semiconductor materials, so the thermal stress leads to the failure of the components.

Although Kovar or Invar have compatible CTEs and good welding capacity, they suffer from low thermal conductivity and high density, Mo-Cu also has high density. Therefore, the aluminum-matrix composites which are reinforced with ceramic particles can be appropriate solution for electronic

* e-mail: o.yaghobizadeh@edu.ikiu.ac.ir packaging and thermal management applications due to high thermal conductivity, compatible CTEs and light weight ${ }^{5}$.

Besides the features of the utilized matrix, one of the crucial factors which affects the mechanical and physical properties of such composites are the type of the utilized reinforcement and the chemical interaction between the reinforcement and matrix $^{6}$. Various types of ceramic reinforcements have been used as the reinforcement phase in the aluminum-matrix composites such as oxides $\left(\mathrm{Al}_{2} \mathrm{O}_{3}, \mathrm{Y}_{2} \mathrm{O}_{3}\right)$, nitrides $\left(\mathrm{Si}_{3} \mathrm{~N}_{4}\right.$, AlN), carbides $(\mathrm{TiC}, \mathrm{SiC})$, hydrates $\left(\mathrm{TiH}_{2}\right)$ and borides $\left(\mathrm{TiB}_{2}\right)^{7,8}$. Among the mentioned reinforcements, $\mathrm{TiC}$ is one of the best choices, because has unique properties like low density, high hardness, good wettability and negligible tendency to react with $\mathrm{Al}^{9}$.

Casting routes ${ }^{10}$, powder metallurgy ${ }^{11}$, in situ synthesis ${ }^{12}$ and spray forming ${ }^{13}$ have been utilized for the fabrication of AMCs. Each of these methods has its own advantages and disadvantages. For example, the casting route is an economical method, however non-uniform distribution of the reinforcement phase and interfacial reactions are the main disadvantages of $\mathrm{it}^{14-19}$.

Among the press-based methods, powder metallurgy is one of the most popular ones. Reduction of the probable chemical reactions between the matrix and the reinforcement during the fabrication process, uniform distribution of the reinforcement particles in the matrix, good tailoring and requiring inexpensive and available facilities are the main privileges of this method compared to the others. 
One of the stages of fabrication via traditional PM is sintering. As it's known, in order to gain high density and reach to the culmination of properties, the shaped samples must be sintered at optimum conditions. Inadequate sintering temperature and duration lead to the remaining of the porosities in the structure and eventually the deterioration of the properties. On the other side, increasing the sintering temperature and duration lead to the increased probability of the reactions which can occur between the reinforcement and the matrix. Also, the obtained coarse grains deteriorate the properties of the final composite ${ }^{5,9}$.

Microwave-assisted sintering method is a novel sintering route which is fundamentally different with the traditional sintering processes. In traditional sintering methods, the sintering driving force is supplied through external elements (resistance heating) and the radiation of them reaches to the sample via conduction and convection mechanism. But in Microwave-assisted sintering process, the sample absorbs the microwave's power itself and converts its energy to the heat within the sample volume itself ${ }^{9}$. So, by decreasing the sintering duration, the grain growth is under control and reaching to a uniform microstructure, with the optimized properties is completely possible.

According to the best of the author's knowledge, no report has been published so far which investigates the thermal and electrical conductivities of the Al-TiC composite fabricated through microwave-assisted sintering method. Therefore, in this current research, the Al-TiC composite is fabricated through microwave-assisted sintering method and the electrical, thermal and mechanical properties of sintered Al-TiC composites have been investigated.

\section{Experimental Procedure}

In this research, aluminum powders (Sigma Aldrich, particle size $<5 \mu \mathrm{m}$, purity: $99.5 \%$ ) and sub-micron $\mathrm{TiC}$ powders (Luoyang Zhengjie Science \&Technology Industry Trade Co. Ltd., china, purity: 99.9\%) were utilized. In order to investigate the effects of reinforcement's amount and sintering duration through microwave-assisted sintering process on the electrical, thermal and mechanical properties and also the microstructure of the Al-TiC composites, the samples were prepared according to Table 1 and were sintered through microwave oven. The starting materials were mixed by a planetary ball mill (Retsch PM200, $150 \mathrm{rpm}$ ) with the speed of $150 \mathrm{rpm}$ for $1 \mathrm{~h}$ in a tungsten carbide cup, under high purity argon atmosphere. The ball: powders ratio was adjusted to $1: 10$. Then, the suspension was dried at 80 / for 24 hours. The dried and mixed powders were disagglomerated by a 100 mesh sieve and then were pressed by an isostatic press under the load of $120 \mathrm{MPa}$. Eventually, the samples were embedded at a substrate which contains $\mathrm{SiC}$ and graphite and were sintered in a $2.45 \mathrm{GHz}$ microwave furnace for various durations.
After the sintering process, the samples were weighed and their densities were measured according to the Archimedes method. The phase analysis of the samples was conducted via X-ray diffractometry (XRD, X'Pert Pro MPD, PANalytical) via $\mathrm{Cu} \mathrm{K}$ radiation. The microstructure analysis was performed by scanning electron microscopy (SEM, VEGA \TESCANLMU) and also a light microscope which was equipped with a camera (Leica DFC480) and imaging software (Image-Pro MC v6.0). The hardness of the samples was calculated via the Brinell method (GNEHM- SWISS Rock, American) under the load of $30 \mathrm{~N}$ and the dwell time of 10 seconds. Electrical resistance of the samples was measured by a 2-point probe method by using a high-resistance meter (model 4339B, Agilent Technologies, Santa Clara, CA, USA).

Thermal conductivity of samples was measured by means of a relative steady-state technique, in an experimental set up (model HT01, Deghat Azma corp). It must be mentioned that all the samples were polished and then etched prior to any analysis. The entire test had been done for 10 times and the average value was reported as the final data for each test. It's noteworthy that experimental design was carried out via Minitab 14 software.

\section{Results and Discussion}

The results of the phase analysis of the samples 2 and 8 are illustrated in Fig. 1. Samples contain $\mathrm{Al}$ and $\mathrm{TiC}$ phases. S. Shimada et al. ${ }^{20}$ has reported, the oxidation behavior of $\mathrm{TiC}$ in both wet and dry oxygen at 300-400/. Their results have shown that $\mathrm{TiC}$ decomposes to $\mathrm{TiO}_{2}$ according to the following equation ${ }^{21,22}$ :

$$
\mathrm{TiC}+2 \mathrm{O}_{2}=\mathrm{TiO}_{2}+\mathrm{CO}_{2}
$$

On the other side, J. Viala ${ }^{23}$ has also submitted the following equation for the stability of TiC:

$$
13 A l+3 T i C=3 A l_{3} T i+A l_{4} C_{3}
$$

There are at least two oxygen sources in the microwaveassisted sintering process method: one of them is the entrapped oxygen between $\mathrm{Al}$ and $\mathrm{TiC}$ particles when the samples pressed and the other is the diffused oxygen to the graphite bed.

The formation of the two phases including $\mathrm{Al}_{4} \mathrm{C}_{3}$ and $\mathrm{TiO}_{2}$ not only decreases the mechanical properties of the samples, but also deteriorates the electrical and thermal properties of them.

The Gibbs free energy of the reactions ${ }^{1}$ and ${ }^{2}$ are shown in Fig. 2. Although, these reactions are thermodynamically possible, but there is no trace of oxide or intermetallic phase in the composites. The phase analysis of composites (fig. 1) and line scan analysis of interface between matrix and TiC particle for sample 9, confirm this fact (Fig. 3). The 
Table 1. Various properties of samples.

\begin{tabular}{ccccccc}
\hline Sample No & $\begin{array}{c}\text { TiC vol. } \\
\mathbf{\%}\end{array}$ & $\begin{array}{c}\text { Time } \\
(\mathbf{m i n})\end{array}$ & $\begin{array}{c}\text { Density } \\
\left(\mathbf{g r} / \mathbf{m m}^{\mathbf{3}}\right)\end{array}$ & $\begin{array}{c}\text { Hardness } \\
(\mathbf{B H N})\end{array}$ & $\begin{array}{c}\text { Electrical conductivity } \\
(\% \mathbf{I A C S})\end{array}$ & $\begin{array}{c}\text { Thermal conductivity } \\
\text { (W/m.c) }\end{array}$ \\
\hline 1 & 4 & 3 & 95.14 & $215.0 \pm 10$ & $7.5 \pm 0.8$ & $177.00 \pm 11$ \\
2 & 4 & 5 & 91.52 & $189.5 \pm 12$ & $31.2 \pm 3.2$ & $240.22 \pm 13$ \\
3 & 4 & 8 & 91.32 & $144.1 \pm 8$ & $40.1 \pm 2.9$ & $250.00 \pm 9$ \\
4 & 8 & 3 & 98.77 & $239.4 \pm 7$ & $6.4 \pm 0.6$ & $157.70 \pm 10$ \\
5 & 8 & 5 & 97.97 & $224.5 \pm 9$ & $26.0 \pm 2$ & $206.00 \pm 8$ \\
6 & 8 & 8 & 92.87 & $194.5 \pm 11$ & $28.6 \pm 1.4$ & $234.00 \pm 14$ \\
7 & 12 & 3 & 93.06 & $203.5 \pm 3$ & $4.2 \pm 0.5$ & $150.00 \pm 11$ \\
9 & 12 & 5 & 96.89 & $215.2 \pm 8$ & $18.7 \pm 1$ & $191.00 \pm 12$ \\
\hline
\end{tabular}

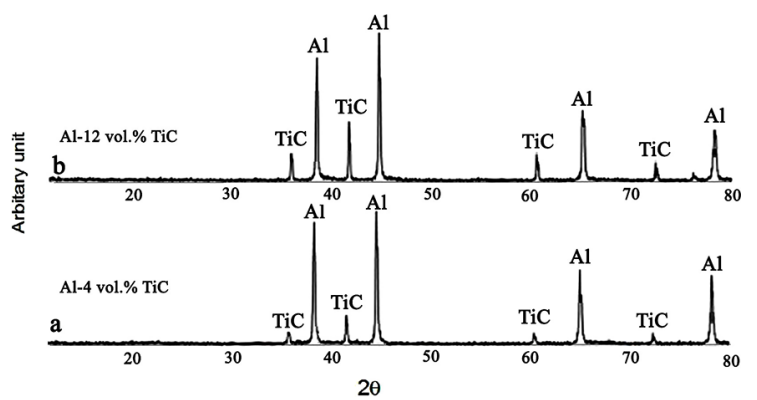

Figure 1. Infrared absorption spectra of the PVdF-CTFE $10 \%$ membranes. The inset indicates the temperature and pressure at which the hot pressing process was conducted.

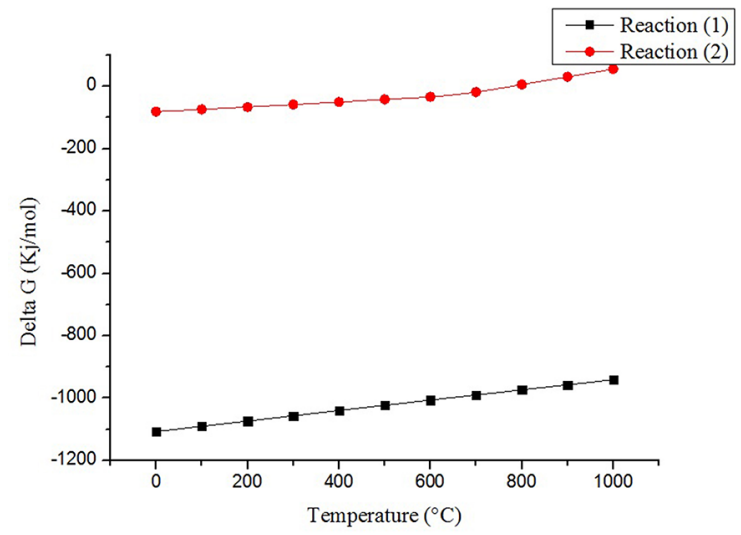

Figure 2. Curves of Gibbs free energy with temperature for reactions 1 and 2 .

shortened sintering duration of this method is the main reason that neither $\mathrm{TiO}_{2}$ nor $\mathrm{Al}_{4} \mathrm{C}_{3}$ was formed.

The SEM images and the X-Rays maps of the sample's surfaces including the samples 4 are illustrated in Figs. 4. The EDS analyses of points 1 and 2 (in fig. 4) are shown in Fig. 5, here white and gray regions belong to $\mathrm{TiC}$ and $\mathrm{Al}$ phases, respectively. Also, the SEM images and the X-Rays maps of the sample's surfaces including the samples 7 are illustrated in Figs. 6.

As it's obvious, the distribution of the reinforcement phase in the samples with 8 vol. \% is more uniform and by increasing its content up to $12 \mathrm{vol} . \%$, their agglomeration is quite visible. As shown in Figs. 4and 6, increasing the amount of reinforcement leads to the increase in the porosity content. In addition, the comparison of the SEM images (Figs.4and 7) has shown that increasing the sintering duration leads to the reduction of the porosity content in the structure. These behavior are in accordance with the submitted values in Fig. 8 .

Also, as it's evident from the light microscope images (Fig. $9(\mathrm{a}, \mathrm{b})$ ), increasing the sintering duration leads to the grain growth of the matrix. As a matter of fact, as long as the submicron $\mathrm{TiC}$ particles are distributed over the matrix uniformly, they could act beneficial and inhibit severe grain growth (fig. 9(c)). But, the addition of the TiC, more than 12 vol. \% has no effect on the inhibition of grain growth (fig. 9(d)) due to their agglomeration and non-uniform distribution. With respect to the obtained results, it can be concluded that the lowest grain growth and the highest density is related to the sample with 8 vol. \% of TiC which was sintered for 3 minutes.

The results of the hardness test are listed in Table 1. The effect of reinforcement content and sintering duration on the hardness are also depicted in Fig. 10. As it's obvious, the sample contains 8 vol. $\%$ of TiC and was sintered for 3 minutes, dedicated the highest amount of hardness. This property has been deteriorated by increasing the reinforcement content up to $12 \mathrm{vol}$ \%. In addition, it can be observed that increasing the sintering duration has a negative effect on the hardness of the samples and the highest hardness was obtained for the sintering duration equal to 3 minutes.

The observed increasing in the hardness by increasing the reinforcement content is attributed to the dispersion strengthening effect of the $\mathrm{TiC}$ particles. In fact, by increasing the reinforcement content, the density of the dislocations is increased in the $\mathrm{Al}$ matrix ${ }^{24}$.

Excessive increase in the reinforcement content not only decreases the resistance of the composite's matrix, but also introduces more crack initiation's locations and eventually decreases the load-bearing capacity of the composite ${ }^{25,26}$. As it can be seen from figs. 4 and 6 , by increasing the amount 

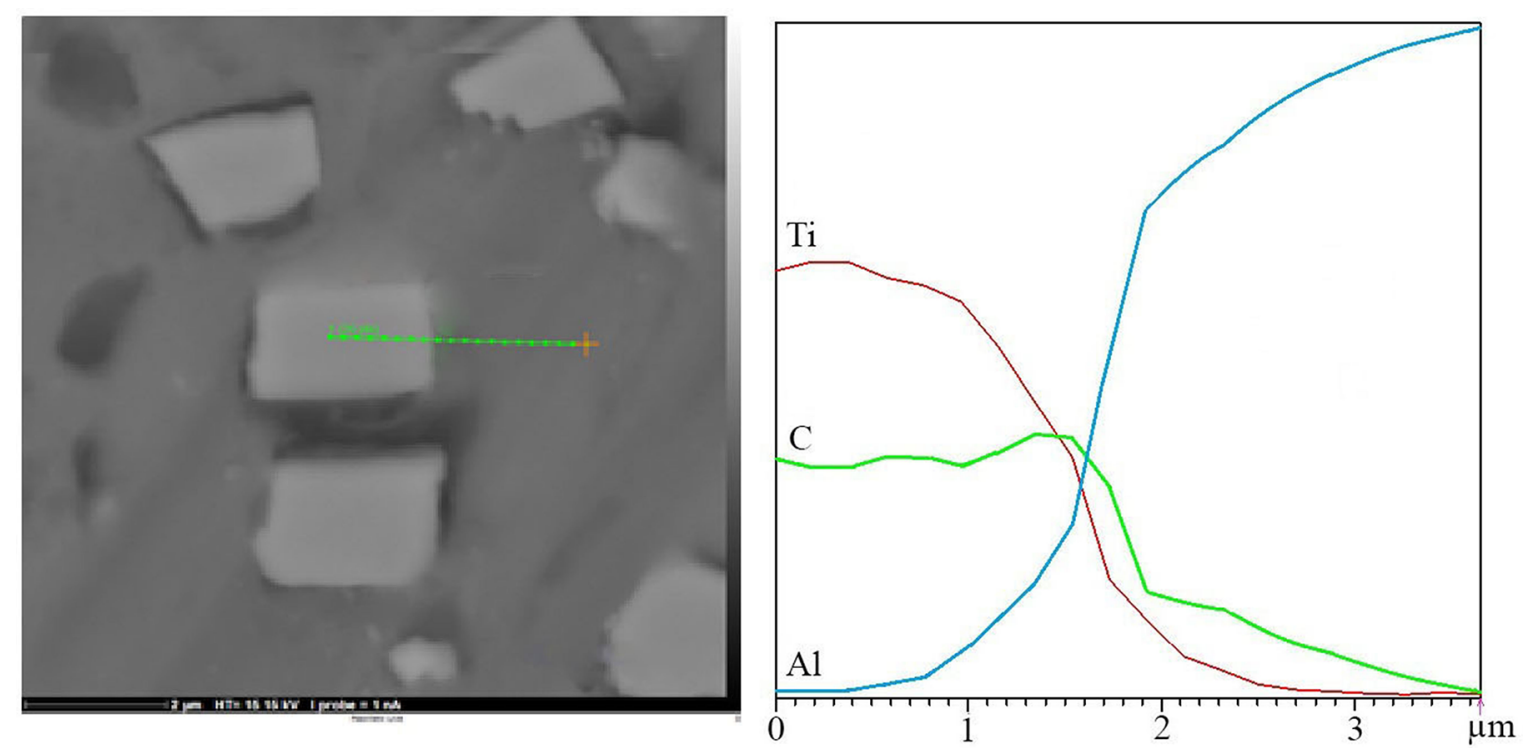

Figure 3. Microstructure and line scan analysis of interface between matrix and TiC particle for sample 9.
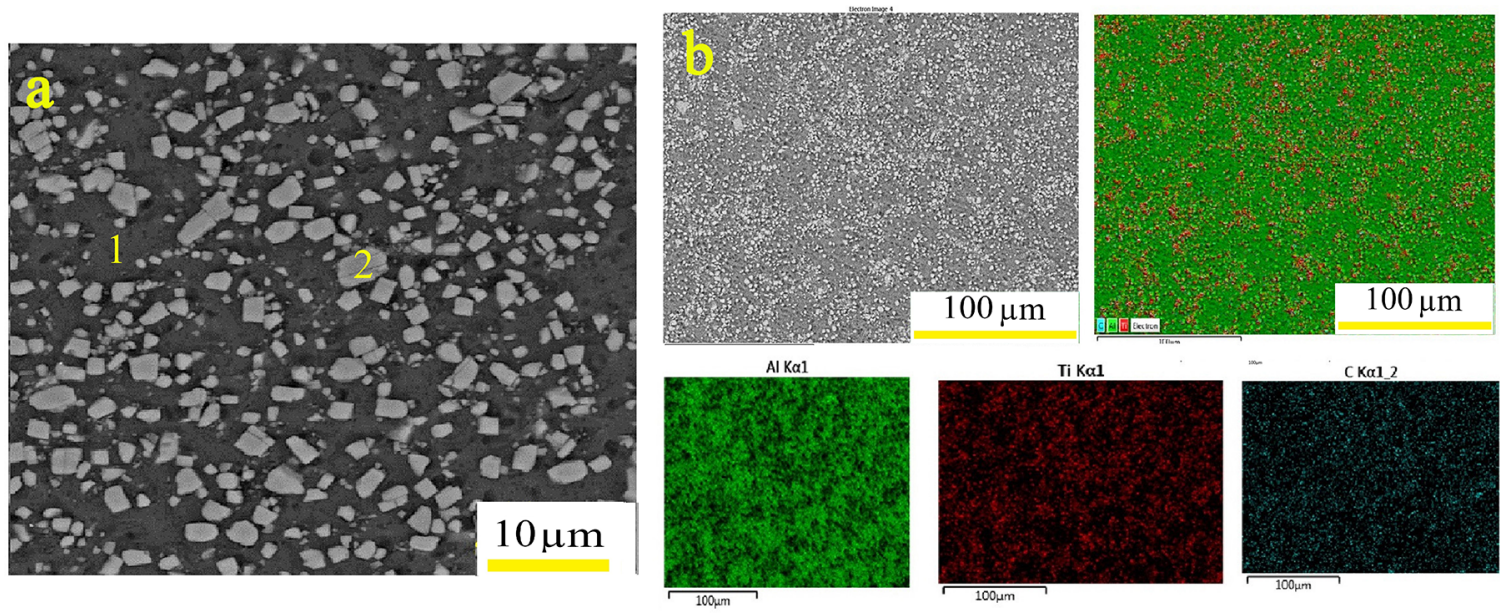

Figure 4. (a) SEM images and (b) the X-Rays maps of sample 4.
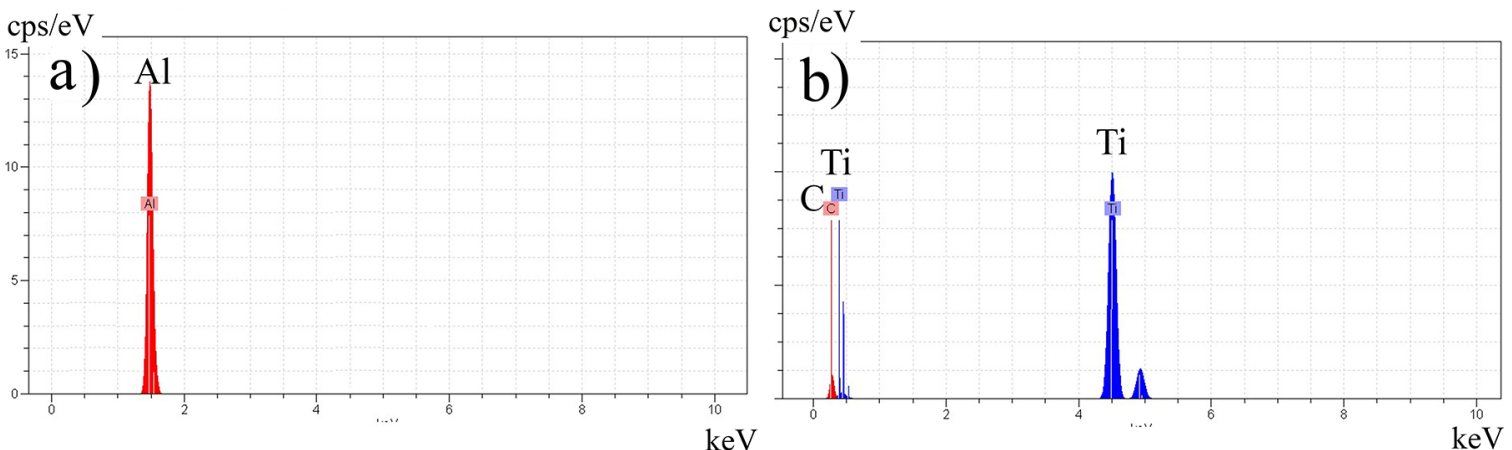

Figure 5. EDS analysis of the points (a) 1 and (b) 2 in figure 4 . 

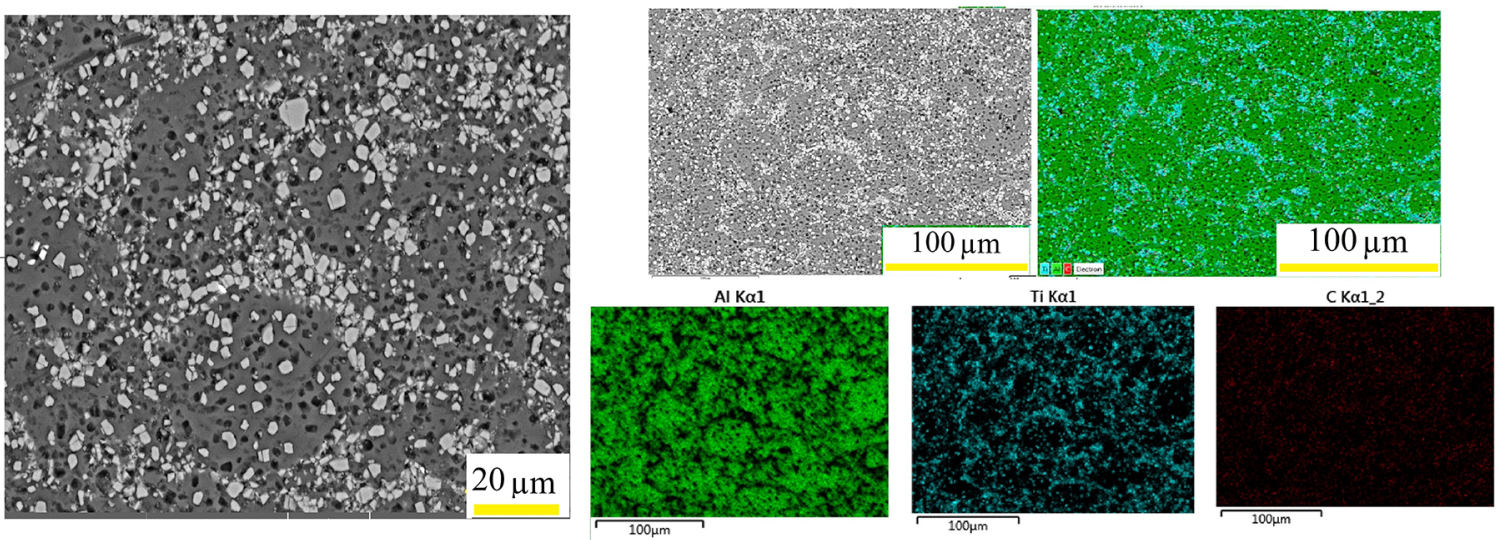

Figure 6. (a) SEM images and (b) the X-Rays maps of sample 7.

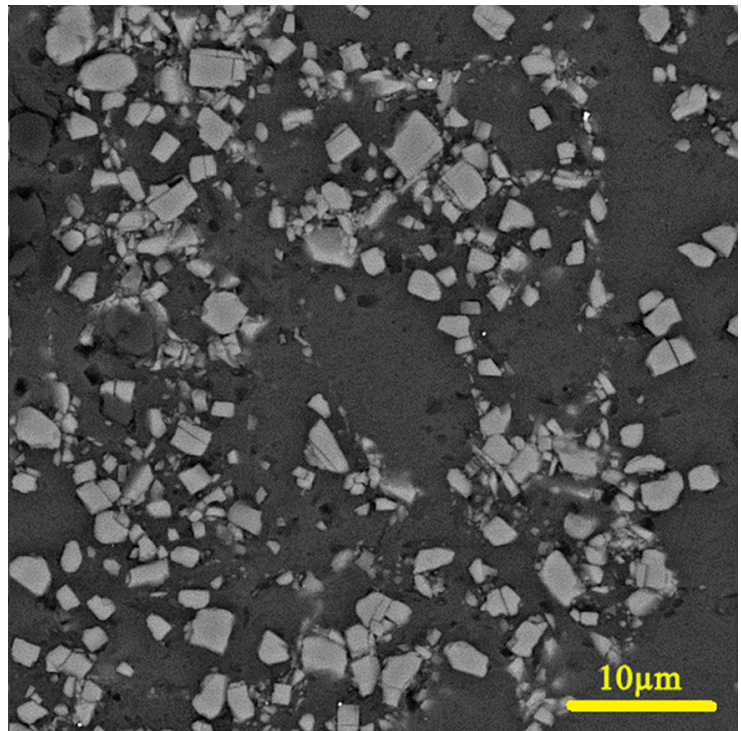

Figure 7. (a) SEM images of sample 6.

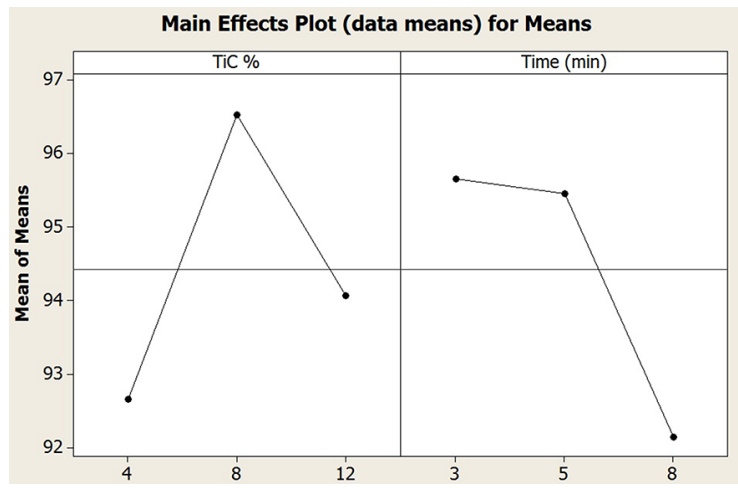

Figure 8. The effect of reinforcement content and sintering duration on the density of samples.

of reinforcements, their uniform distribution in the matrix of the composite have been begun to decrease. Therefore, the contact between the $\mathrm{TiC}$ particles is increased and the ductile aluminum of the matrix cannot protect the particles any more. As a result, the cracks propagated among the $\mathrm{TiC}$ particles, easily ${ }^{27}$.

Although increasing the sintering duration has a positive impact on the density of the samples, it was expected that the reduction of porosity leads to the increase of hardness, but the ultimate result was utterly in the opposition of what was expected. Actually, the negative effect of increasing the sintering duration on the hardness of the composite can be attributed to the growth of the matrix's grains (fig. 9) due to the increased diffusion of the atoms. According to the Hall-Petch equation, over growth of the grains leads to the decrease of hardness.

The measured electrical conductivity of the sintered Al-TiC composites with different sintering durations and different amount of reinforcements are listed in Table 1. As it's evident from Fig. 11, the electrical conductivity of the composites is faced with a descending trend by increasing the amount of TiC.

Porosities and slight oxidation are the main reasons behind the low electrical conductivity of the samples without additives ${ }^{28}$. The interaction of free electrons and nucleus of metals is weak, therefore, free electrons can move easily without interruption and that's why the electrical conductivity of metals is quite good. But in carbides, the electrons are bonding firmly to the nucleus and can't move so easily and that's why these materials have low electrical conductivity ${ }^{29,30}$. So it can be justified that increasing the amount of carbide eventually leads to the reduction of electrical conductivity of the final composite.

$\mathrm{TiC}$ reinforcement particles act as obstacles in front of electron's movement. Reduction of electrical conductivity by increasing the amount of $\mathrm{TiC}$ can be assessed from different aspects: (i) as it was mentioned, the intrinsic electrical resistance of $\mathrm{TiC}$ is one of the main reasons for this behavior, (ii) by increasing the amount of TiC, the density of the induced dislocations due to the variation between $\mathrm{Al}$ and TiC's thermal expansion coefficient, increases. The increase of dislocation's density leads to the electron scattering on 

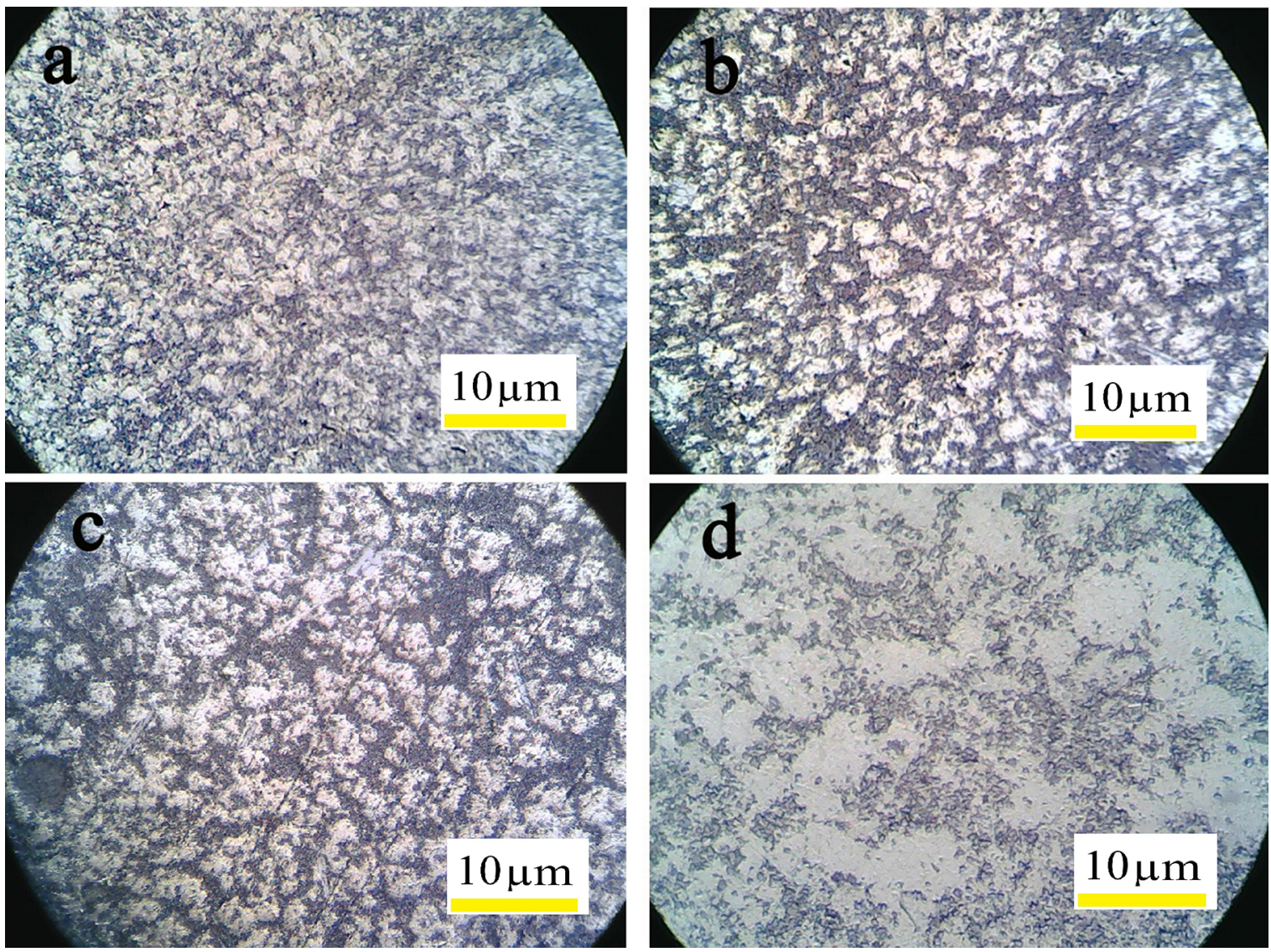

Figure 9. Light microscope images of (a) sample 1 (b), sample 3, (c) sample 6 and (d) sample 9.

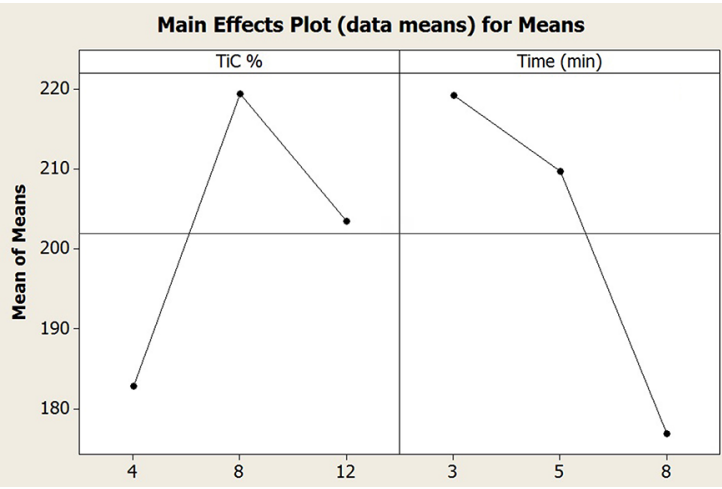

Figure 10. The effect of reinforcement content and sintering duration on the Hardness of samples.

the $\mathrm{Al}-\mathrm{TiC}$ surface and as a result, causes the reduction of the electrical conductivity and at last, (iii) presence of TiC particles actually reduces the size of the matrix's grains which means the increase of grain boundaries ${ }^{30}$ and finally the reduction of electrical conductivity.

As it's shown in fig. 11, increasing the sintering duration have a positive impact on the electrical conductivity of the samples and it can be attributed to the reduction of porosity in the structure.

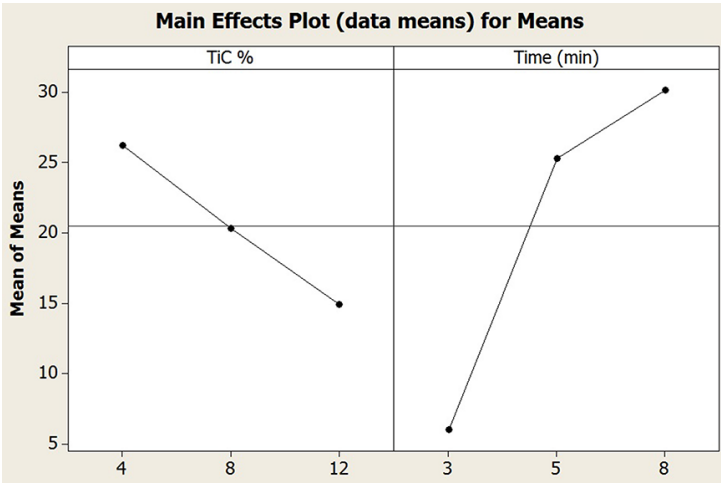

Figure 11. The effect of reinforcement content and sintering duration on the electrical conductivity of samples.

The obtained data for thermal conductivity of the samples are listed in Table 1. The effect of the amount of reinforcement and sintering duration on the thermal conductivity are shown in Fig. 12. It was clarified that increasing the amount of reinforcement and sintering duration have negative and positive effects on the thermal conductivity of the samples, respectively.

With respect to the fact that the thermal conductivity of $\mathrm{TiC}$ is lower than metal matrix's value, it was expected that 


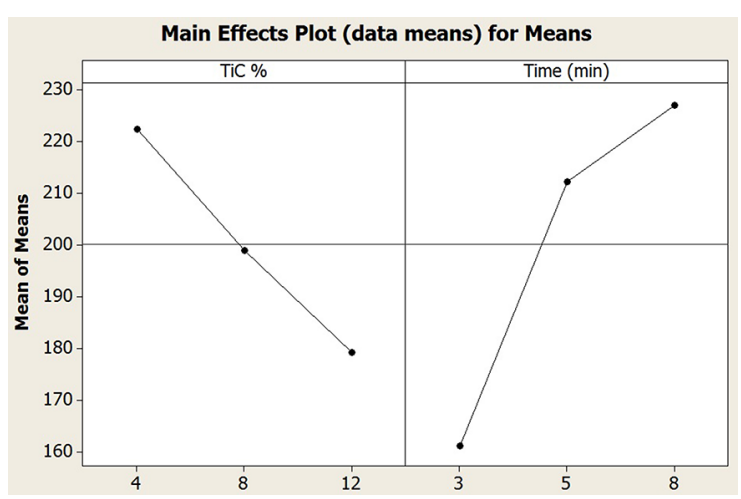

Figure 12. The effect of reinforcement content and sintering duration on the thermal conductivity of samples.

increasing the amount of reinforcement has a negative effect on the thermal conductivity of the composite. A schematic of heat conduction in metals are shown in Fig. 13.

Several factors can reduce the thermal conductivity, the most important of them are: phonon/defect scattering, phonon/ interface scattering and phonon/phonon scattering. In crystalline structures, presence of defects leads to the phonon scattering, phonon reflection and/or phonon diffraction. Therefore, by shortening the mean free path, thermal conductivity will reduce $^{31,32}$. In this kind of scattering, each defect acts as an obstacle in front of phonons transfer.

In phonon/interface scattering mechanism, since the TiC particles have dimensions, so they present an interface or disconnection. In composites, this kind of scattering in inevitable and depends to the TiC particle's features. Therefore, increasing the amount of reinforcement provokes more scatterings.

\section{Conclusion}

In this research, Al-TiC composite was fabricated through rapid microwave process and the following results have been obtained:

- The addition of the TiC, more than 12 vol. $\%$ had no effect on the inhibition of grain growth, due to their agglomeration and non-uniform distribution of particles.

- Due to the shortened sintering duration in the microwave sintering method, there was no trace of pernicious phases including $\mathrm{TiO}_{2}$ and $\mathrm{Al}_{4} \mathrm{C}_{3}$.

- The highest electrical and thermal conductivities were achieved for the composite containing $4 \mathrm{vol}$. $\% \mathrm{TiC}$ which was sintered for 8 minutes. Also the highest hardness and density were achieved for the composite containing 8 vol. $\%$ TiC which was sintered for 3 minutes.

- Increasing the sintering duration had a negative effect on the hardness of the composites due to the growth of the matrix's grains.

- Increasing the amount of TiC, led to the reduction of thermal and electrical conductivities of the samples while increasing the sintering duration increased the mentioned properties.
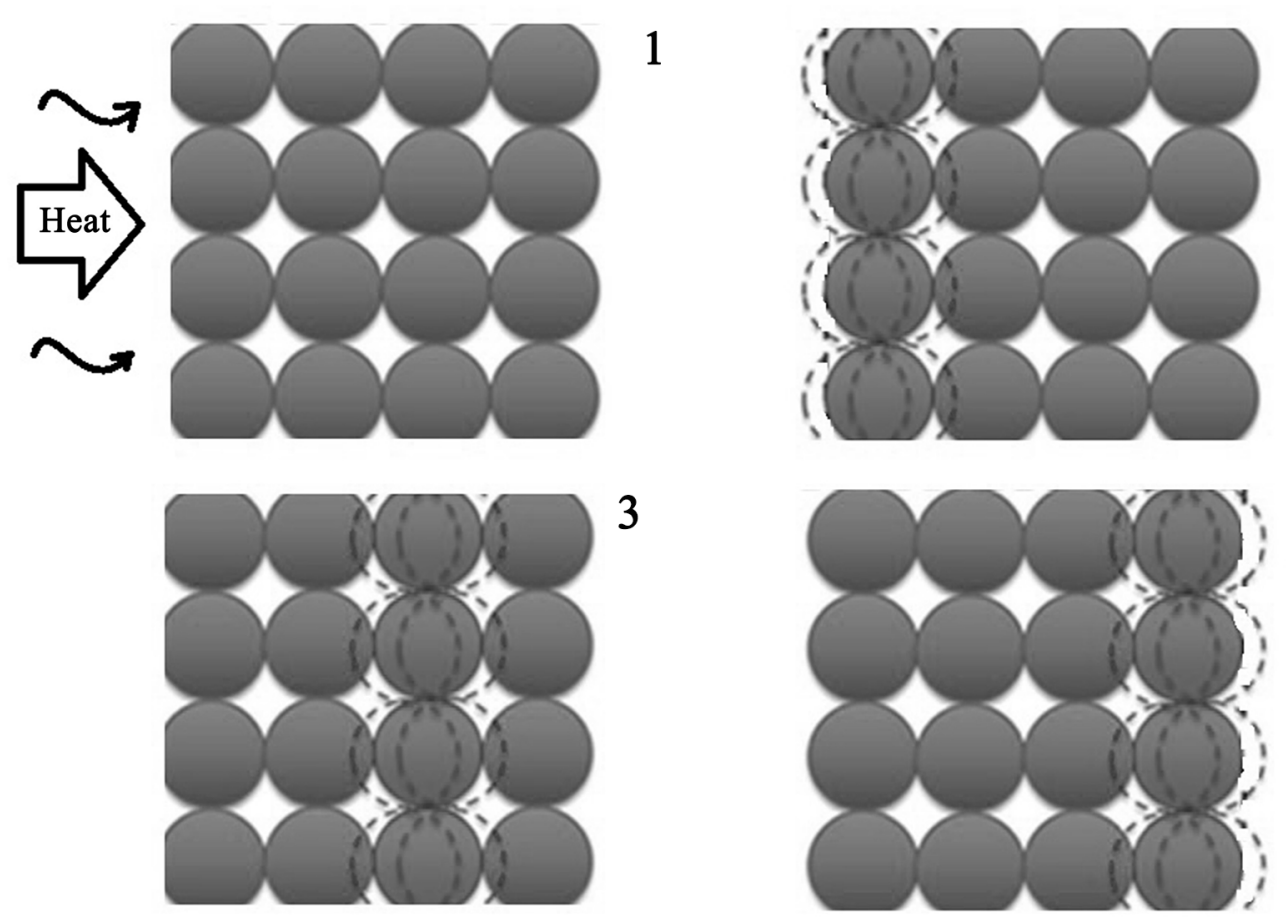

Conduction and

Radiation

ヘ

Figure 13. The schematic of thermal conductance in a crystalline material. 
- $\quad$ By changing the amount of $\mathrm{TiC}$ and sintering duration, electrical and thermal conductivities were variable from $4.2 \%$ IACS to $40.1 \%$ IACS and from $150 \mathrm{~W} / \mathrm{m} . c$ to $250 \mathrm{~W} / \mathrm{m} . \mathrm{c}$, respectively, without deteriorating its mechanical properties.

\section{References:}

1. Kaftelen H, Ünlü N, Göller G, Lütfi Öveolu M, Henein H. Comparative processing-structure-property studies of $\mathrm{Al}-\mathrm{Cu}$ matrix composites reinforced with TiC particulates. Composites Part A: Applied Science and Manufacturing. 2011;42(7):812824.

2. Samer N, Andrieux J, Gardiola B, Karnatak N, Martin O, Kurita H, et al. Microstructure and mechanical properties of an Al-TiC metal matrix composite obtained by reactive synthesis. Composites Part A: Applied Science and Manufacturing. 2015;72:50-57.

3. Omar AA, El-Shennawy M, Ayad M. Study of Wear Behavior of as Cast TiC/7075 Composite. International Journal of Mechanical Engineering. 2015;4(4):45-52.

4. Veeravalli RR, Ramanaiah N, Sarcar MMM. Mechanical and tribological properties of AA7075-TiC metal matrix composites under heat treated (T6) and cast conditions. Journal of Materials Research and Technology. 2016;5(4):377-383.

5. Zhang Q, Liu D, Chen G, Xiu Z, Wu G. Performance and application of SiCp/Al composites for electronic packaging. In: Proceedings of 16th IEEE International Symposium on the Physical and Failure Analysis of Integrated Circuits; 2009 Jul 6-10; Suzhou, Jiangsu, China. p. 252-255.

6. Yaghobizadeh O, Baharvandi HR, Ahmadi AR, Aghaei E. Development of the Properties of $\mathrm{Al} / \mathrm{SiC}$ Nano-Composite Fabricated by Stir Cast Method by Means of Coating SiC Particles with Al. Silicon. 2018; DOI: https://doi.org/10.1007/ s12633-018-9867-3

7. Srivastava A. Recent Advances in Metal Matrix Composites (MMCs): A Review. Biomedical - Journal of Scientific \& Techical Research. [Internet]. 2017. Available from: <http:// biomedres.us/fulltexts/BJSTR.MS.ID.000236.php>. Access in: $18 / 04 / 2018$.

8. Kumar A, Mahapatra MM, Jha PK. Fabrication and Characterizations of Mechanical Properties of Al- $4.5 \% \mathrm{Cu} / 10 \mathrm{TiC}$ Composite by InSitu Method. Journal of Minerals and Materials Characterization and Engineering. 2012;11:1075-1080.

9. Ghasali E, Fazili A, Alizadeh M, Shirvanimoghaddam K, Ebadzadeh T. Evaluation of Microstructure and Mechanical Properties of Al-Tic Metal Matrix Composite Prepared By Conventional, Microwave and Spark Plasma Sintering Methods. Materials (Basel). 2017;10(11). pii: E1255.

10. Lloyd DJ. Particle reinforced aluminium and magnesium matrix composites. International Material Reviews. 1994;39(1):123.
11. Padmavathi C, Upadhyaya A. Densification, microstructure and properties of supersolidus liquid phase sintered 6711 Al-SiC metal matrix composites. Science of Sintering. 2010;42(3):363-382.

12. Dinaharan I, Murugan N. Dry sliding wear behavior of AA6061/ZrB2 in-situ composite. Transactions of Nonferrous Metals Society of China. 2012;22(4):810-818.

13. Laha T, Agarwal A, McKechnie T, Seal S. Synthesis and characterization of plasma spray formed carbon nanotube reinforced aluminum composite. Materials Science and Engineering: A. 2004;381(1-2):249-258.

14. Ghasali E, Nouranian H, Rahbari A, Majidian H, Alizadeh M, Ebadzadeh T. Low Temperature Sintering of AluminumZircon Metal Matrix Composite Prepared by Spark Plasma Sintering. Materials Research. 2016;19(5):1189-1192.

15. Kala H, Mer KKS, Kumar S. A Review on Mechanical and Tribological Behaviors of Stir Cast Aluminum Matrix Composites. Procedia Materials Science. 2014;6:1951-1960.

16. Ibrahim IA, Mohamed FA, Lavernia EJ. Particulate reinforced metal matrix composites - a review. Journal of Materials Science. 1991;26(5):1137-1156.

17. Liu YB, Lim SC, Lu L, Lai MO. Recent development in the fabrication of metal matrix-particulate composites using powder metallurgy techniques. Journal of Materials Science. 1994;29(8):1999-2007.

18. Majidian H, Ghasali E, Ebadzadeh T, Razavi M. Effect of Heating Method on Microstructure and Mechanical Properties of Zircon Reinforced Aluminum Composites. Materials Research. 2016;19(6):1443-1448.

19. Çetin A, Kalkanli A. Effect of solidification rate on spatial distribution of $\mathrm{SiC}$ particles in A356 alloy composites. Journal of Materials Processing Technology. 2008;205(1-3):1-8.

20. Shimada S, Mochidsuki K. The oxidation of TiC in dry oxygen, wet oxygen, and water vapor. Journal of Materials Science. 2004;39(2):581-586.

21. Korablev SF. Chemical and kinetic features of oxidation of powder titanium carbide. Refractories and Industrial Ceramics. 1999;40(11-12):534-536.

22. Das G, Chatterjee DK, Lipsitt HA. Electron irradiation damage in TiC. Journal of Materials Science. 1981;16(12):3283-3291. DOI: http://dx.doi.org/10.1007/BF00586288

23. Viala JC, Vincent C, Vincent H, Bouix J. Approche thermodynamique de l'interaction chimique entre l'aluminium et le carbure de titane. Materials Research Bulletin. 1990;25(4):457-464.

24. Lijay KJ, Selvam JDR, Dinaharan I, Vijay SJ. Microstructure and mechanical properties characterization of AA6061/TiC aluminum matrix composites synthesized by in situ reaction of silicon carbide and potassium fluotitanate. Transactions of Nonferrous Metals Society of China. 2016;26(7):1791-1800. 
25. Sivaraj M, Selvakumar N. Experimental Analysis of Al-TiC Sintered Nanocomposite on EDM Process Parameters Using ANOVA. Materials and Manufacturing Processes. 2016;31(6):802-812.

26. Rizkalla HL, Abdulwahed A. Some mechanical properties of metalnonmetal Al-SiO2 particulate composites. Journal of Materials Processing Technology. 1996;56(1-4):398-403.

27. El-Amoush AS. Effect of aluminum content on mechanical properties of hydrogenated Mg-Al magnesium alloys. Journal of Alloys and Compounds. 2008;463(1-2):475-479.

28. Santos SF, De Andrade MC, Sampaio JA, Da LuzAB, Ogasawara T. Thermal study of TiO2-CeO2 yellow ceramic pigment obtained by the Pechini method. Journal of Thermal Analysis and Calorimetry. 2007;87(3):743-746.
29. Schoenitz M, Patel B, Agboh O, Dreizin EL. Oxidation of aluminum powders at high heating rates. Thermochimica Acta. 2010;507508:115-122.

30. Wang QZ, Cui CX, Lu DM, Bu SJ. Fabrication and properties of a novel $\mathrm{ZnO} / \mathrm{Cu}$ composite. Journal of Materials Processing Technology. 2010;210(3):497-503.

31. Weisenberger M, Martin-Gullon I, Vera-Agullo J, Varela-Rizo $\mathrm{H}$, Merino C, Andrews R, et al. The effect of graphitization temperature on the structure of helical-ribbon carbon nanofibers. Carbon. 2009;47(9):2211-2218.

32. Lim S, Yoon SH, Mochida I. Surface Modification of Carbon Nanofiber with High Degree of Graphitization. Journal of Physical Chemistry B. 2004;108(5):1533-1536. 